\title{
Behavior of Frame-Stiffened Composite Panels with Damage
}

\author{
Dawn C. Jegley* \\ NASA Langley Research Center, Hampton, VA 23681
}

\begin{abstract}
NASA, the Air Force Research Laboratory and The Boeing Company have worked to develop new low-cost, light-weight composite structures for aircraft. A Pultruded Rod Stitched Efficient Unitized Structure (PRSEUS) concept has been developed which offers advantages over traditional metallic structures. In this concept, a stitched carbon-epoxy material system has been developed with the potential for reducing the weight and cost of transport aircraft structure by eliminating fasteners, thereby reducing part count and labor. Stitching and the use of thin skins with rod-stiffeners to move loading away from the morevulnerable outer surface produces a structurally efficient, damage tolerant design. This study focuses on the behavior of PRSEUS panels loaded in the frame direction and subjected to severe damage in the form of a severed central frame in a three-frame panel. Experimental results for a pristine two-frame panel and analytical predictions for pristine two-frame and three-frame panels as well as damaged three-frame panels are described.
\end{abstract}

\section{Introduction}

The goal of NASA's Environmentally Responsible Aviation Project (ERA) is to simultaneously reduce fuel burn, emissions and noise to the community for large commercial aircraft of the future. A key factor in achieving the fuel burn and emissions goals is reducing structural weight. Any configuration of aircraft, from a traditionally shaped tube-with-wings to advanced configurations such as a hybrid wing body (HWB), will benefit from reduced structural weight. Airframe weights have recently been reduced through the use of advanced composite materials, but new and different architectures are being developed that are appreciably lighter than aluminum designs or stateof-the-art carbon-epoxy material systems.

A structural concept showing promise in reducing aircraft weight is the Pultruded Rod Stitched Efficient Unitized Structure (PRSEUS) configuration, shown in Fig. 1. This concept is being studied under ERA through a partnership between NASA and The Boeing Co. Trade studies indicate that significant weight savings can be achieved through the use of PRSEUS technology. ${ }^{1}$

PRSEUS is an integral panel assembly produced outside of an autoclave. PRSEUS uses dry warp-knit fabric layers stitched together to create the panel preform such that all materials can be co-cured without the use of stiff inner moldline tooling. Skins, flanges, and webs are composed of layers of graphite material forms that are prekitted into multi-ply stacks using Hercules, Inc. AS4 fibers. Several stacks of the prekitted material are used to build up the desired thickness and configuration. Specimens are stitched together using Vectran fibers. Stiffener flanges are stitched to the skin and no mechanical fasteners are used for joining. To maintain the panel geometry during fabrication, first stiffeners and then the skin are placed in a stitching tool for assembly prior to moving to a curing tool for consolidation in the oven. The stringers run in one direction and consist of flanges and webs with a unidirectional carbon fiber rod at the top of the web. AS4 carbon fiber overwraps surround the rod. The frames are hats filled with Rohacell foam are perpendicular to the stringers.. The prekitted stacks used in the PRSEUS skin and stiffeners have approximately $44 \%$ of $0-, 44 \%$ of $\pm 45-$, and $12 \%$ of 90 -degree plies. Stack thickness is approximately 0.052 inches. The panels are infused with HexFlow VRM 34 resin. ${ }^{1}$ The pultruded rods are fabricated from Toray unidirectional T800 fiber with a 3900-2B resin. In the current design, the 0-degree orientation of the skin is parallel to the frames. An exploded view of the intersection between a PRSEUS stringer and frame is shown in Fig. 1. The lines of stitching where the carbon fabric layers are held together are shown.

\footnotetext{
${ }^{*}$ Senior Aerospace Engineer, Associate Fellow, AIAA, Structural Mechanics and Concepts Branch, mail stop 190.
} 


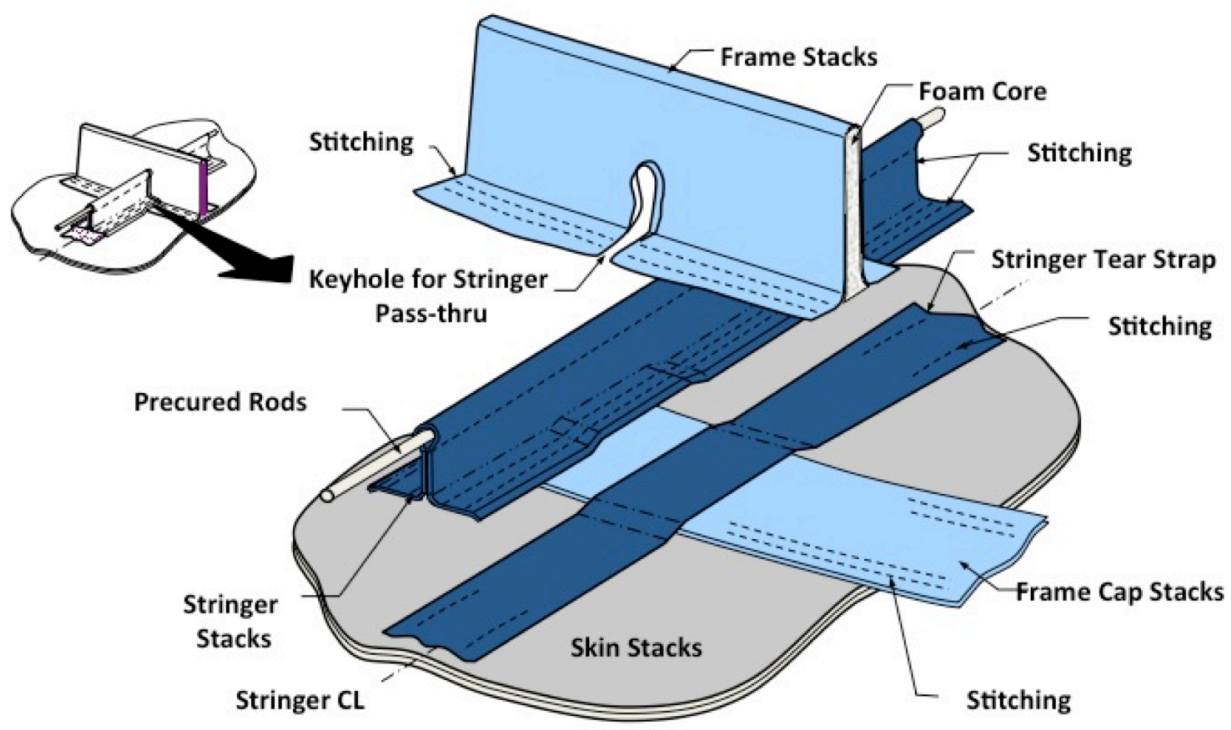

Figure 1. PRSEUS stiffener intersection.

This concept eliminates all fasteners from the panel, thereby removing all the holes and doublers associated with fasteners, as well as improving the ease of assembly and reducing part count. An additional benefit of this concept is the damage arrestment capability of the stitching. This arrestment capability allows the PRSEUS configuration to increase the load carrying capability, and also allows the use of a post-buckled skin since the stitches prevent delamination between the skin and the flange. This feature allows the skin to be minimum thickness (one stack) and the stiffeners to carry more of the load. In addition to the strength benefits of a unitized panel, the PRSEUS stringer is optimized for fuselage loading with a continuous 0-degree pultruded rod at the top of the stringer, and the frame has deep sections raising the panel's neutral axis for bending capability and providing an uninterrupted load path. The continuous rod passes through a slit or keyhole in the frame to minimize loss of stability and optimize load transfer. PRSEUS can be applied to wing structures, barrel fuselages, and nontraditional shapes such as the center section of a HWB aircraft. Earlier studies involving stitched technology describing PRSEUS panel behavior under applied tension or compression are presented in References 2-10.

The focus of this paper is the behavior of panels loaded in the frame direction in tension and compression in the pristine condition and with a severed frame. Evaluation of the frame components began with analysis and testing of a series of short single-frame specimens, then progressed to a two-frame, compression specimen. The information from these studies is used to predict the behavior of three-frame panels.

\section{Test Specimens, Procedure and Instrumentation}

Single-frame and two-frame specimens were subjected to compressive loading to evaluate their buckling behavior, failure modes, and failure loads. First, a four-frame, seven-stringer panel was fabricated to cut up into single-stiffener specimens. ${ }^{1}$ The single-frame specimens were 16.5 inches long with the frame aligned in the loading direction and including two stringers perpendicular to the frame. The specimens were 10 inches wide. The geometry of the stringer and frame are shown in Fig. 2. The skin of each specimen was one stack of material with the 0 -degree orientation aligned with the frame. Stringers had a 3.4-inch-wide flange, a 0.104 inch-thick web and were 1.5 inches tall. The nominal diameter of the pultruded rod was 0.375 inches and the nominal thickness of the overwrap was 0.052 inches. Flange thickness was half the web thickness. Frames were 6 inches tall and consisted of a foam-filled hat with 0.5 inches of foam surrounded by two stacks of material. One stack of additional material was added under each flange and labeled as a tear strap for the stringers and a cap for the frame, as identified in Fig. 1. Both the tear strap and cap covered the same area of skin as the stiffener flange. The two-frame specimen was 92 inches long and 30 inches wide and contained the same stiffener geometry as the single-stiffener specimens. 


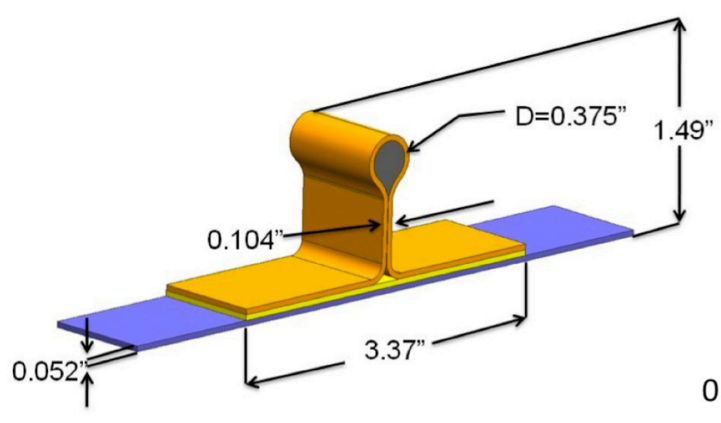

a) Stringer

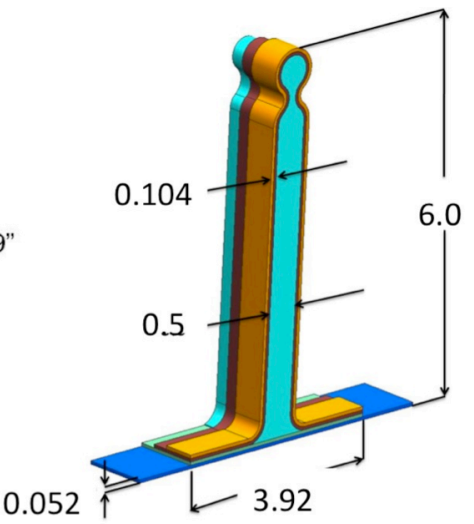

b) Frame

Figure 2. PRSEUS stiffeners. All dimensions are in inches.

Stringer spacing was 6 inches and frame spacing was 20 inches. A single-frame specimen is shown in Fig. 3 and the two-frame specimen is show in Fig. 4.

Prior to testing, each end of each compression specimen was potted in 1.0-inch-deep epoxy compound and the ends were ground flat and parallel to each other to ensure uniform load introduction. Edge supports were included on the unloaded edges since these edges would be supported in real aircraft parts. Each specimen was loaded to failure in compression at a rate of approximately $0.005 \mathrm{in}$./minute. Displacement and strain gage data were recorded at the rate of $5 \mathrm{~Hz}$ as load was applied. In each test, displacements were measured using three displacement transducers measuring end-shortening. Strain gages were added to the specimens to monitor skin and frame behavior. A video image correlation system was used to capture the displacements and strains of the unstiffened side of the two-frame specimen. Video images were recorded at a rate of $1 \mathrm{~Hz}$.

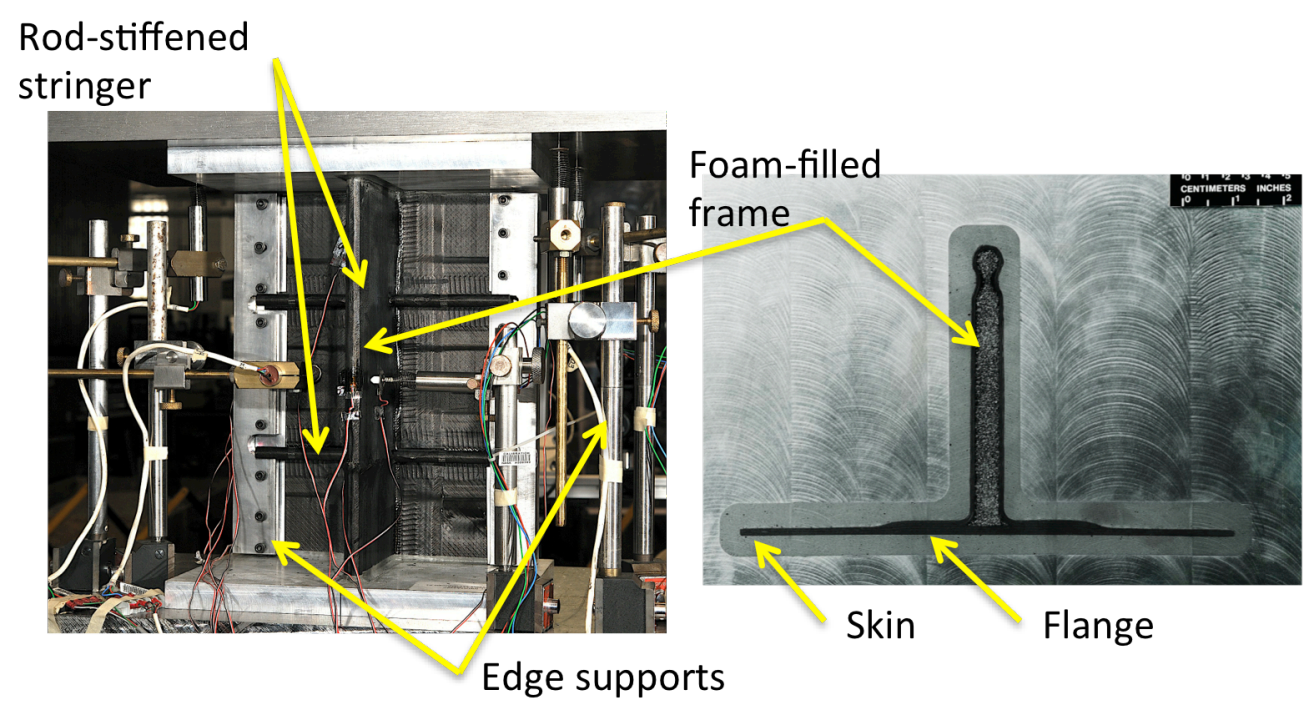

Figure 3. Single-frame PRSEUS specimen. 


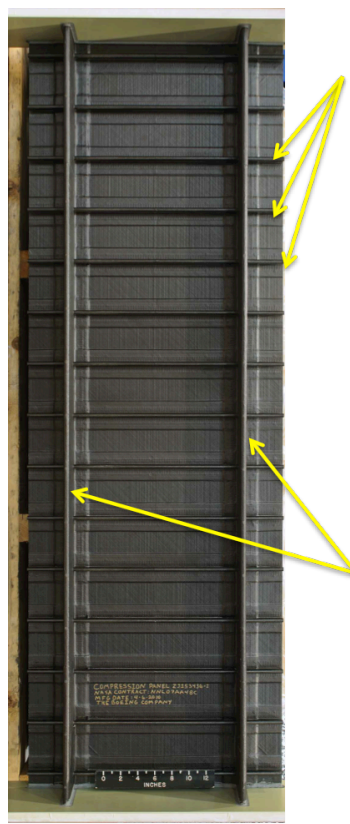

Stiffened side of panel
Rod-stiffened stringer

Foam-filled

frame

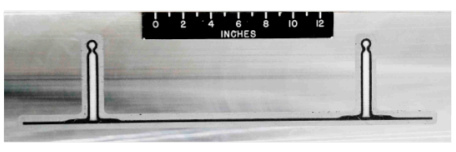

Panel cross section

Figure 4. Two-frame panel.

\section{Analysis Approach}

Finite element analyses of the PRSEUS two-frame panel were conducted to compare analytical results to the test data of the two-frame panel before extrapolating the analytical approach to the three-frame panel. Linear, buckling, and geometrically nonlinear analyses were conducted using the finite element code STAGS. ${ }^{11}$ In all cases, the region inside the potting was simulated by restraining lateral and out-of-plane degrees of freedom. Out-of-plane degrees of freedom were also restrained where edge supports on the unloaded edges prevented global buckling modes from occurring. Element size was nominally 0.25 inches per side. Skin, flanges, and stringer webs were modelled as shell elements. The frames were modelled as sandwich elements (8-node shell elements) and the rod regions were modelled as beam elements. The finite element model of the pristine two-frame panel was first created then modified by adding an additional frame to create the model of the pristine three-frame panel. The models of the pristine two- and three-frame panels are shown in Fig. 5. The skin, flange, and frame elements of the central frame at the axial centerline were then removed from the pristine panel model to represent a severed central frame. The severed region is shown in Fig. 6. Notch tips are not modeled in detail so predicted strains too close to the notch tip will not be reliable. Further refinement of the notch tip would be needed to obtain more accurate notch tip strains. The material properties ${ }^{1}$ for the analysis are shown in Table 1. 


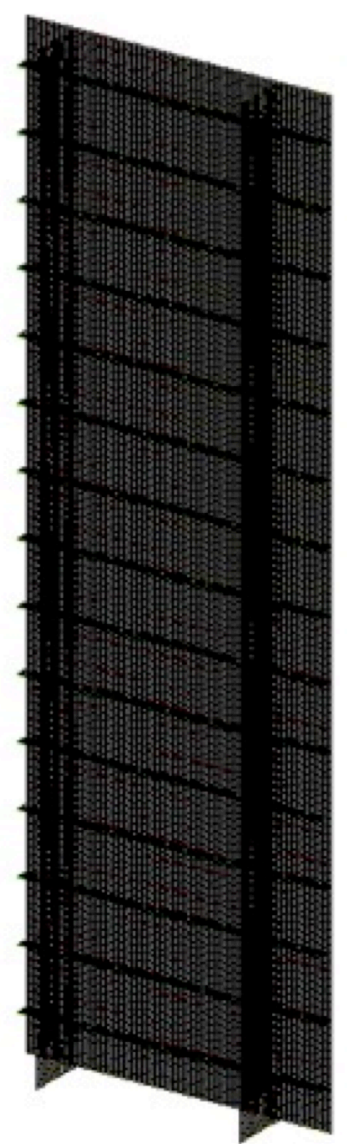

a) Two-frame panel

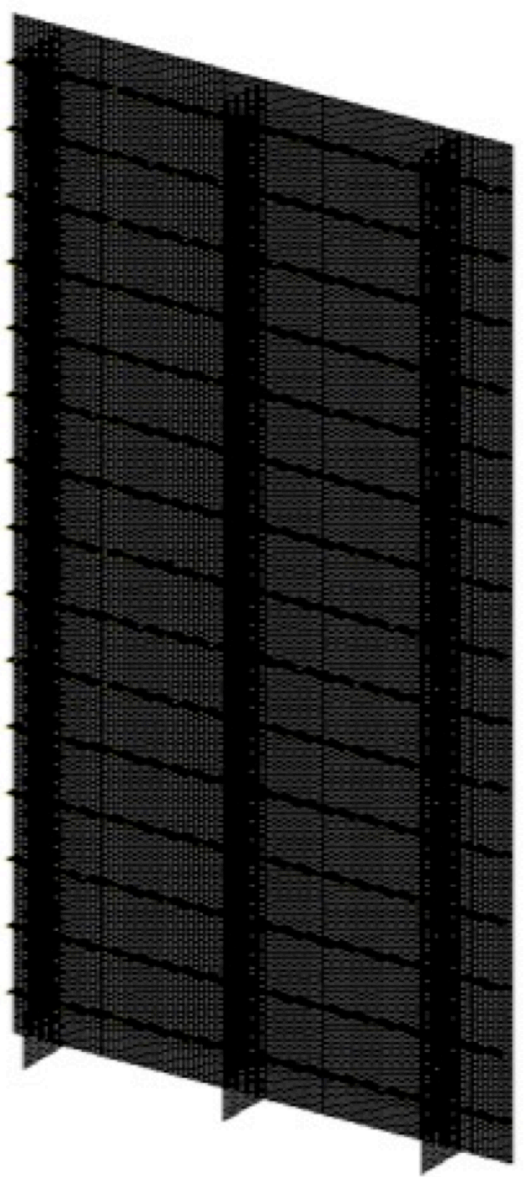

b) Three-frame panel

Figure 5. Finite element models

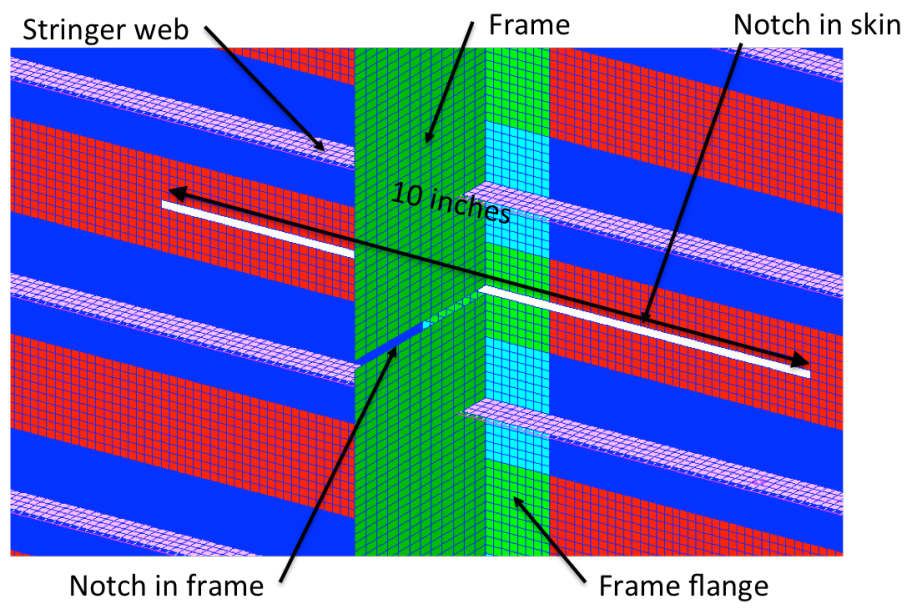

Figure 6. Finite element model showing severed frame. 
Table 1. Nominal Material Properties

\begin{tabular}{lcccc}
\hline \hline Property & $\begin{array}{c}\text { Stack } \\
\text { compression* }\end{array}$ & $\begin{array}{c}\text { Stack } \\
\text { tension* }\end{array}$ & Foam & Rod \\
\hline $\begin{array}{l}\text { Longitudinal } \\
\text { stiffness, Msi }\end{array}$ & 9.23 & 10.25 & 0.0261 & 18.0 \\
\hline $\begin{array}{l}\text { Transverse } \\
\text { stiffness, Msi }\end{array}$ & 4.66 & 5.07 & 0.0261 & 1.0 \\
\hline $\begin{array}{l}\text { Shear stiffness, } \\
\text { Msi }\end{array}$ & 2.26 & 2.48 & 0.0102 & 6.0 \\
\hline Poisson's ratio & 0.397 & 0.403 & 0.29 & 0.2 \\
\hline * 0.052 inches thick, [44/44/12] percent $0 / 45 / 90$ & & \\
\hline
\end{tabular}

\section{Results and Discussion}

A discussion is presented of the single- and two-frame experimental and analytical work for pristine structure. Then the analytical results are presented for three-frame pristine panels and finally three-frame damaged panels.

\section{A. Single-Frame Specimens}

Preliminary evaluations were conducted on four single-frame compression specimens where the frame spanned three stringer bays as described in References 1 and 5. A single-frame specimen is shown in Fig. 3. The main purpose of these single-frame compression tests was to find the failure load of the specimen and to correlate initial analysis predictions with the empirical results. Two specimens were tested statically and two were fatigued prior to final static testing. Testing of all four of the specimens showed that the frame can meet the loading requirements as dictated by the global analysis described in Reference 1, regardless of fatigue cycling. Each single-frame specimen supported approximately 80,000 $\mathrm{lb}$. These results also provided insight into the failure mode of the frame under compression.

\section{B. Two-Frame Panel}

After obtaining results from the single-frame specimens that indicated they could withstand the required loads, the next step was to evaluate a two-frame, 15-stringer panel under compressive loading. This panel prior to testing is shown in Fig. 4. The test data and a preliminary analysis of this panel are presented in Reference 12.

Nonlinear finite element analysis predicted that the panel would continue to support load in the frames after the skin between the stiffeners buckled. The eigenvector corresponding to the minimum eigenvalue is shown in Fig. 7. Analysis predicts a buckling load of approximately 13,200 lb. Analysis to loads greater than the buckling load indicates that stress concentrations occur at the panel edges, at the flange edges, and at the keyhole where the frame and stringer intersect.

The panel was loaded to failure in axial compression. A video image correlation system was used to monitor full field displacements for the central 42 inches of the panel during loading. The out-of-plane deformation of the panel measured at 147,000 lb, immediately prior to failure, is shown in Fig. 8. The out-of-plane deformation determined from finite element anlaysis is shown in Fig. 9 for the same load level. Buckling between the stiffeners is clearly visible. While the deformation pattern is not exactly the same between the test and the analysis, the displacement magnitudes are the same. Initial panel geometric imperfections influenced the pattern so experimental results are not symmetric in the vertical direction. Analysis did not consider initial geometric imperfections. Overall, the analysis agrees well with the test data. Photographs of the panel after failure are shown in Fig. 10. Failure progressed through the keyhole, flange edges and the panel edge. The panel supported 147,000 lb, or approximately $73,000 \mathrm{lb} /$ frame. 


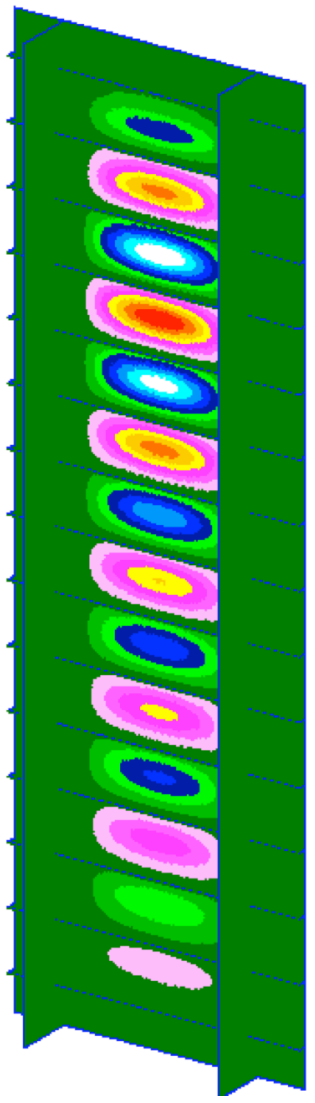

Figure 7. Two-frame panel eigenvector.

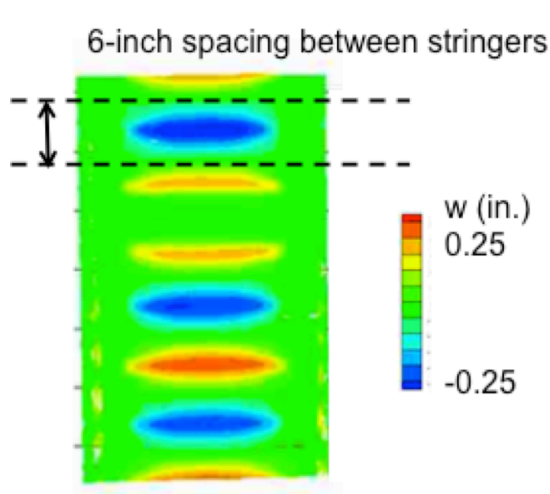

Center 42 inches

Figure 8. Measured out-of-plane deformation of center 42 inches of the two-frame compression panel at a load of $147,000 \mathrm{lb}$ immediately prior to failure.

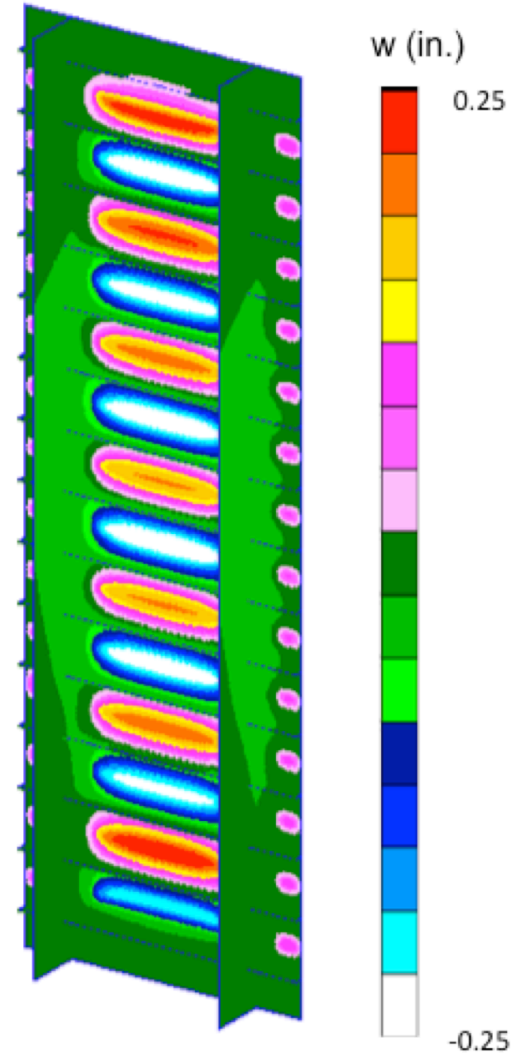

Figure 9. Finite element prediction of outof-plane deformation of two-frame compression panel at a load of $147,000 \mathrm{lb}$ or approximately $73,000 \mathrm{lb} /$ frame. 


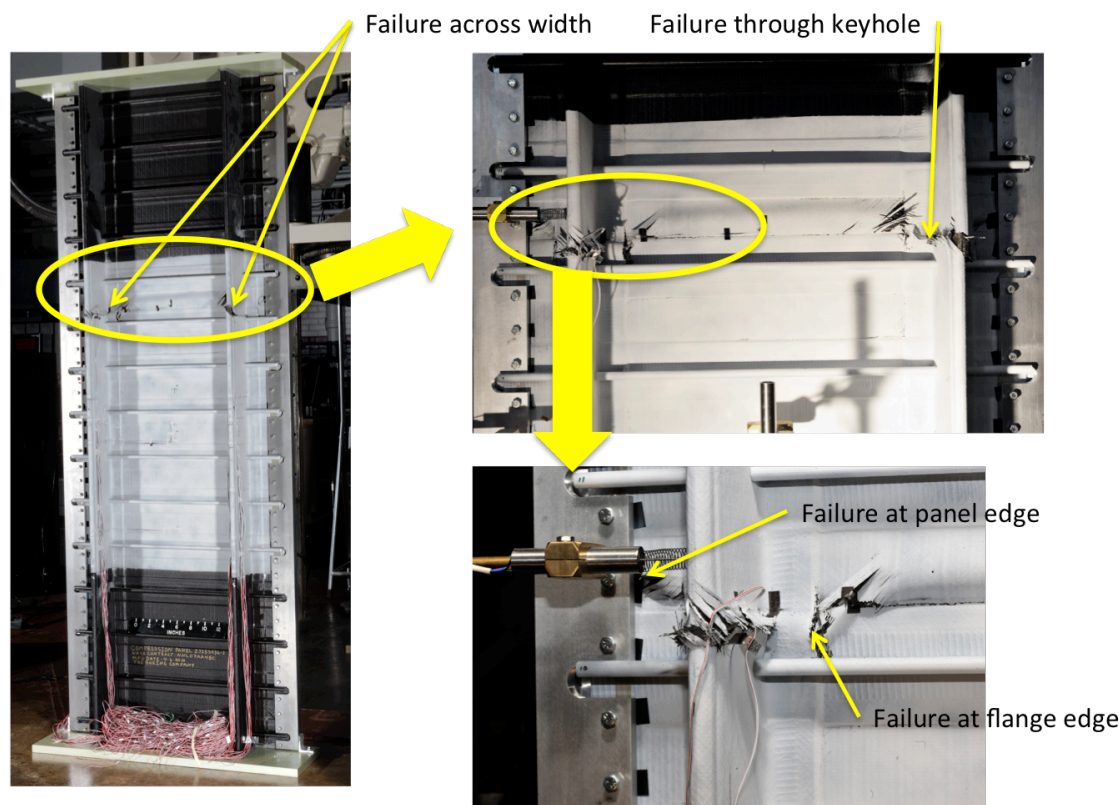

Figure 10. Failure of two-frame compression panel.

\section{Three-Frame Panel}

The next step in evaluating PRSEUS panels loaded in the frame direction is to consider the behavior of damaged panels. A severe damage typically considered for aircraft structure is the condition where a stiffener is fully severed. PRSEUS panels are designed to support Design Limit Load (DLL) even in the presence of severe damage such as a mid-bay-to-mid-bay notch which severs a stringer or frame. In this case, a three-frame panel with the central frame, frame flange, and the skin being fully severed is considered.

The eigenvector corresponding to the minimum eigenvalue for the pristine panel is shown in Fig. 11. Analysis predicts a buckling load of approximately $19,600 \mathrm{lb}$, which is approximately 1.5 times the buckling load of the twoframe panel. A failure load of 1.5 times the failure load of the two-frame panel would be anticipated, resulting in a failure load of approximately 220,000 lb. Out-of-plane displacements at 220,000 lb, based on nonlinear finite element analysis, are shown in Fig. 12. While the skin buckles continue to grow as load is increased past the buckling load, the frames do not buckle.

The skin, flange, and frame elements of the central frame at the axial centerline were then removed from the pristine panel model, representing a severed central frame. The methodology for predicting the failure of the panel with a severed frame is the same as described in Reference 13 where a severed stringer was considered. In the panel described in Reference 13, the 0-degree orientation of the skin was in the loading direction, the same as for the panels which are the subject of the present paper. Since the critical factor in the failure of the stitched panel is the behavior at the stitch lines of the adjacent stringers and since the stitching approach is the same for stringers as for frames, the same methodology applies. Based on the behavior of other stitched panels with similar notches,${ }^{13}$ failure initiation near the notch tip in the frame-stiffened panel would occur when the surface strain reaches $-0.0072 \mathrm{in}$./in. at a location 0.25 inches away from the notch tip. Note that since the skin buckling behavior contributes to the strain in the notch region, the surface strain is used. This strain corresponds to a load of approximately $39,400 \mathrm{lb}$. Surface strains 0.25 inches away from the notch tip are shown as red lines in Fig. 13. The strain pattern near the notch tip is shown in Fig. 14 at a load of 39,422 lb. As expected, the strains decrease rapidly away from the notch tip. 


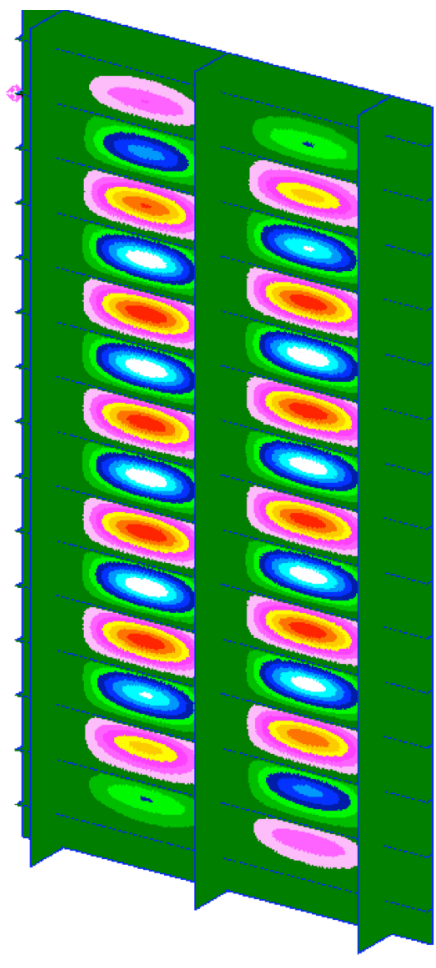

Figure 11. Minimum eigenvector of the three-frame compression panel.

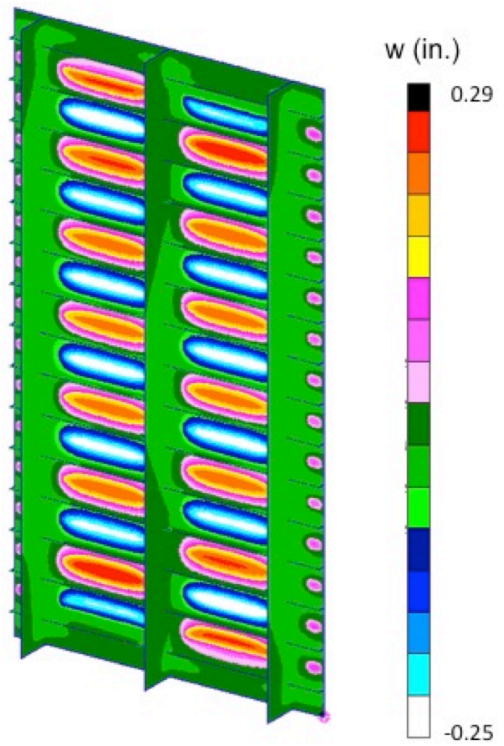

Figure 12. Out-of-plane deformation of three-frame compression panel at a load of $220,000 \mathrm{lb}$.
Crack growth initiates at the notch and is expected to continue until the crack progresses to the flange of the adjacent frame where arrestment is expected to occur. Based on prior studies, ${ }^{13}$ failure at the flange edge is predicted using surface skin strain in the element next to the adjacent flange and is expected to occur when this strain reaches approximately $-0.0059 \mathrm{in} . / \mathrm{in}$. Surface strains in the element adjacent to the flange are shown as blue lines in Fig. 13. A strain of -0.0059 in./in. at the edge of the adjacent flange corresponds to a load of approximately $145,000 \mathrm{lb}$. DUL for the two-frame panel is based on approximately 73,000 $\mathrm{lb} /$ frame, leading to a DUL of $219,000 \mathrm{lb}$ for the pristine threeframe panel, or DLL of $146,000 \mathrm{lb}$ for the pristine three-frame panel, where DUL is 1.5 times DLL. Therefore, the three-frame panel with the severed frame would be required to support 146,000 lb. Based on this analysis, the panel should support $99 \%$ DLL, almost meeting the loading requirement. The strain pattern at the flange region is shown in Fig. 15 at a load of $148,700 \mathrm{lb}$, where the maximum strain value can be seen close to the edge of the flange

A similar approach is used to predict the behavior of a tension-loaded three-frame panel based on a tension-loaded three-stringer panel. ${ }^{10}$ Note that the tension and compression material stack properties are slightly different. Prior to crack progression, the primary difference between the tension and compression panel behavior is the lack of buckling in the tension panel. After initial crack progression in the tension panel, the crack arrested at the adjacent flanges as the load continued to increase, then turned parallel to the flange and stitch line. The arrestment load can be predicted based on the methodology described above but not the crack progression beyond that point. Note that two tension panels are described in Reference 10, one with the 0-degree layers in the skin oriented in the loading direction but two stacks thick, and one with the 0-degree layers in the skin oriented perpendicular to the loading direction but only one stack thick. Both displayed the same behavior and failure mechanisms with similar strains at crack arrestment. There was no strain gage at the notch tip in those panel tests, so crack initiation cannot be predicted based on those results. There was a strain gage on the skin adjacent to the flange in each test so the crack arrestment strain can be used to predict crack arrestment in a three-frame panel. Based on this test, arrestment is assumed to occur when the strain in the skin adjacent to the flange reaches $0.0062 \mathrm{in} . / \mathrm{in}$. 


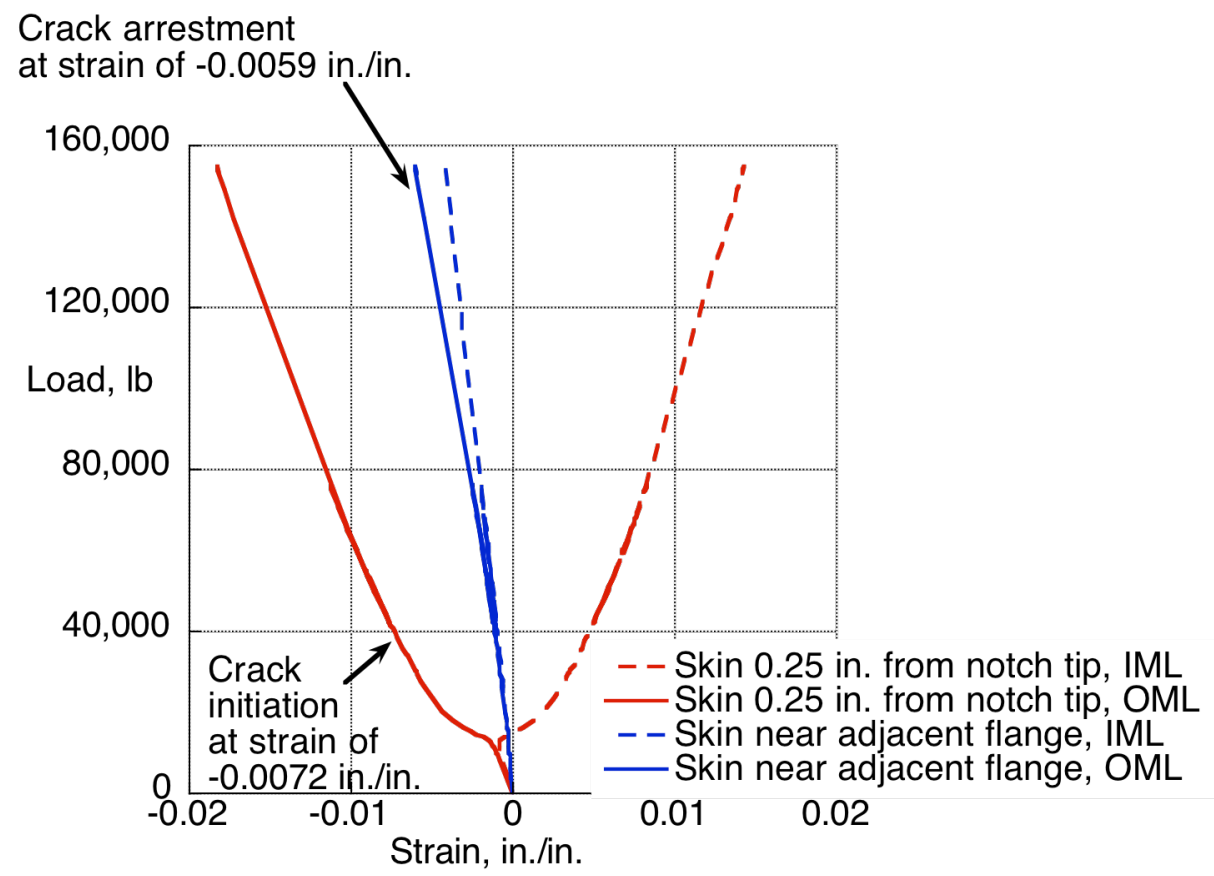

Figure 13. Predicted skin surface strain in the loading direction at critical locations for a threeframe panel with a severed central frame.

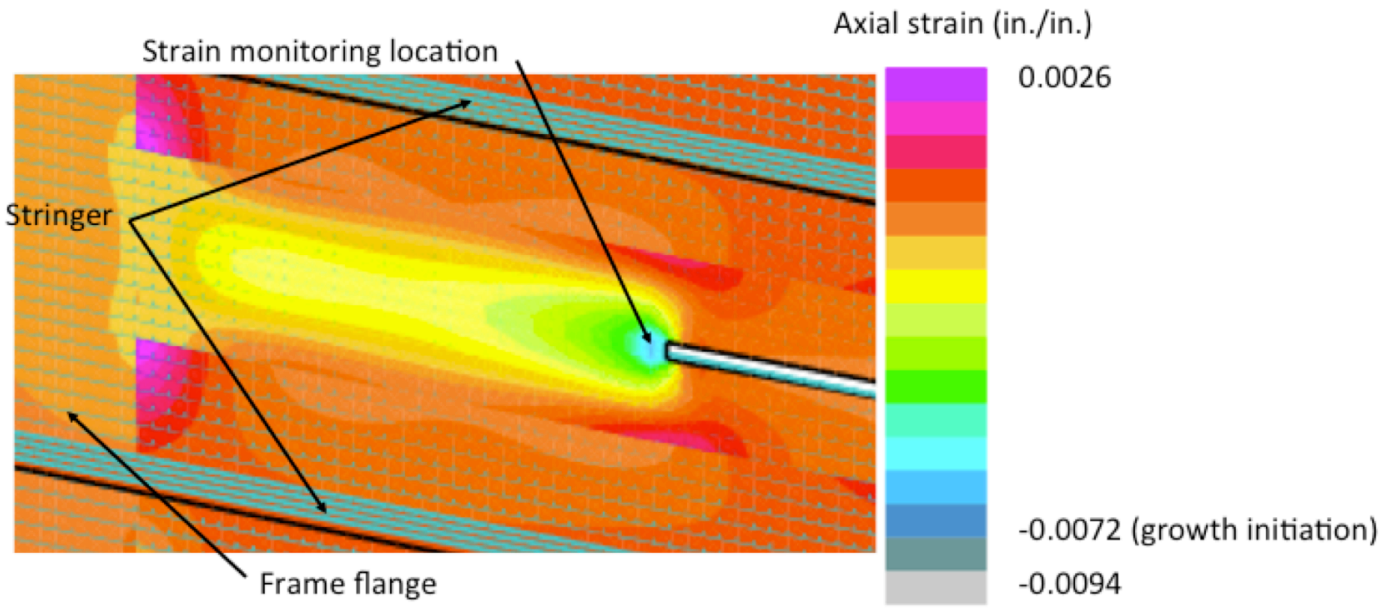

Figure 14. Strain at crack tip at a load of 39, $422 \mathrm{lb}$. 


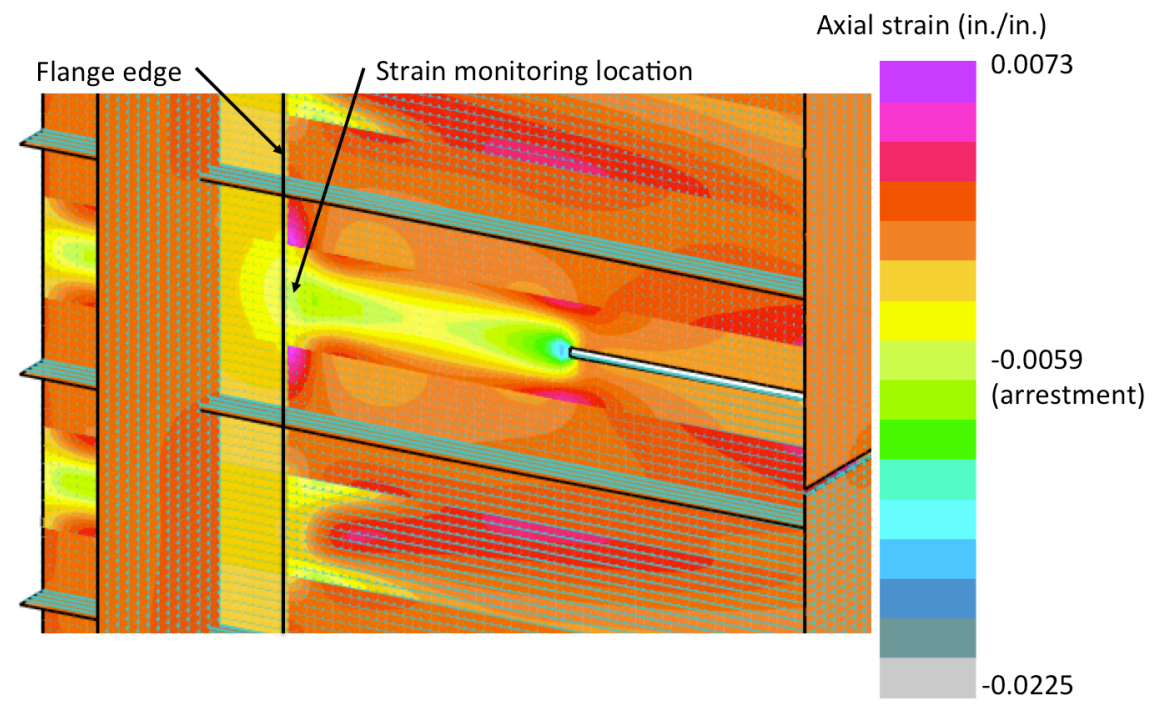

Figure 15. Strain in skin at flange edge at a load of $148,700 \mathrm{lb}$

The strains in the skin at 0.25 inches from the notch tip and adjacent to the frame flange are shown in Fig. 16 for a geometrically nonlinear analysis. The axial strain pattern near the notch tip for a load of 250,000 lb is shown in Fig. 17. At this load, the strain in the element adjacent to the flange is significantly less than the strain when crack arrestment occurred in the stringer-loaded panel. Tension panels display different failure mechanisms than compression panels so this methodology may not apply as well to tension panels as to compression panels. A detailed progressive failure analysis is needed to predict the panel behavior once crack growth starts.

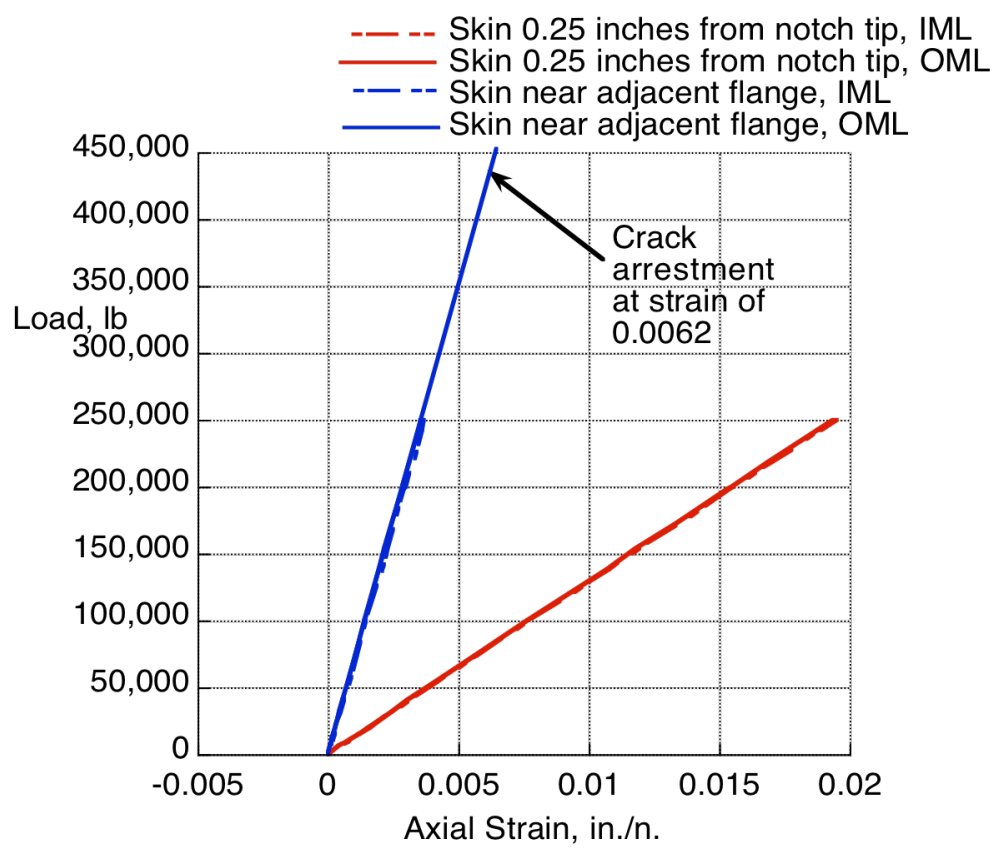

Figure 16. Predicted skin surface strain in the loading direction at critical locations for a three-frame tension-loaded panel with a severed central frame. 


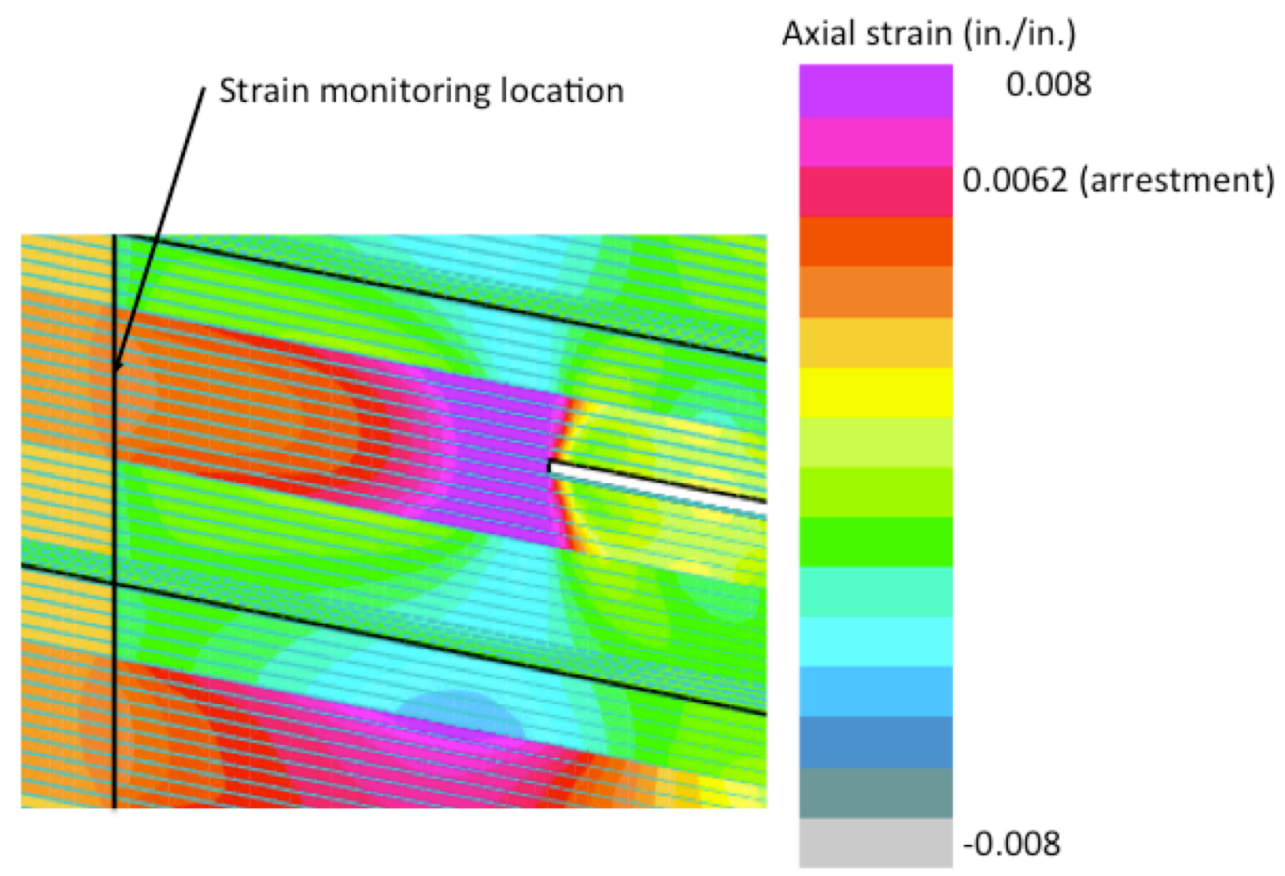

Figure 17. Axial strain in tension-loaded panel at a load of $250,000 \mathrm{lb}$.

\section{Concluding Remarks}

The PRSEUS concept can be applied to almost any type of large-scale aircraft structure and could result in significant weight savings compared to today's state-of-the-art composite construction. However, evaluation of panels with PRSEUS construction must be continued to demonstrate their behavior in the presence of damage. Analytical results are compared to test data and extended to predict the behavior of a panel with a severed frame. Unidirectional compression and tension of PRESUS panels loaded in the frame direction are considered.

In pristine compression-loaded panels, the skin buckles between the stiffeners and eventually the failure initiates at the keyhole through the frame. The frames do not buckle and each frame is expected to support 70,000 to 80,000 lb. In a three-frame panel with a severed central frame, analysis indicates that failure would be expected to initiate at the notch tip and progress to the adjacent frame flange, arrest, and then support increased load so that the panel would still be expected to support approximately DLL, meeting the goal of PRSEUS structural design. All studies to date indicate that PRSEUS damaged structure can support the required loads, making it a viable concept for commercial aircraft applications.

\section{References}

1. Velicki, A., “Damage Arresting Composites for Shaped Vehicles,” NASA CR-2009-215932, Sept. 2009.

2. Air Vehicle Technology Integration Program (AVTIP), Delivery Order 0059: Multi-role Bomber Structural Analysis, AFRL-VA-WP-TR-2006-3067, Krishna Hoffman, MAY 2006, Final Report for 14 December 2004 - 08 May 2006, AFRL-VA-WP-TR-2006-3067.

3. Karal, M., “AST Composite Wing Study - Executive Summary,” NASA/CR-2001-210650, Prepared for NASA, Langley Research Center under Contract NAS1-20546, March 2001.

4. Velicki, A. and Thrash, P.J., "Advanced Structural Concept Development Using Stitched Composites," 49th AIAA/ASME/ASCE/SHS/ASC Structures, Structural Dynamics, and Materials Conference, Apr. 7-10 2008, Schaumburg, IL, AIAA Paper 2008-2329.

5. Jegley, D., "Experimental Behavior of Fatigued Single Stiffener PRSEUS Specimens," NASA TM 2009-215955, Dec. 2009. 
6. Velicki, A., Jegley, D.C., and Thrash P.J., “Airframe Development for the Hybrid Wing Body Aircraft,” 47th AIAA Sciences Meeting, AIAA-2009-932, Jan. 5-8 2009, Orlando, FL.

7. Velicki, A., and Thrash P.J., "Blended Wing Body Structural Concept Development," Aircraft Structural Design Conference, Oct. 14-16 2008, Liverpool, UK.

8. Li, V., and Velicki, A., "Advanced PRSEUS Structural Concept Design and Optimization," 12th AIAA/ISSMO Multidisciplinary Analysis and Optimization Conference, AIAA-2008-5840, Sept. 10-12 2008, Victoria, British Columbia, Canada.

9. Jegley, D.C., Velicki, A., Hansen, D., "Structural Efficiency Of Stitched Rod-stiffened Composite Panels With Stiffener Crippling," 49th AIAA/ASME/ASCE/SHS/ASC Structures, Structural Dynamics, and Materials Conference, Apr. 7-10 2008, Paper No. 2008-2170, Schaumburg, IL.

10. Velicki, A, Yovanof, N., Baraja, J., Linton, K., Ki, V., Hawley, A., Thrash, P., DeCoux, S., and Pickell, R., "Damage Arresting Composites for Shaped Vehicles-Phase II Final Report. NASA CR-2011-216880, Jan. 2011.

11. Rankin, C. C., Loden, W. A., Brogan, F. A., and Cabiness, H. D., "STAGS Users Manual," Rhombus Consultants Group, Inc., Palo Alto, CA 94303, January, 2007.

12. Yovanof, N.P., and Jegley, D.C., "Compressive Behavior of Frame-Stiffened Composites Panels," 52nd AIAA/ASME/ASCE/SHS/ASC Structures, Dynamics, and Materials Conference, Paper No. 2011-1913, April 4-7 2011, Denver, CO.

13. Jegley, D., "Structural Efficiency and Behavior of Pristine and Notched Stitched Structure," presented at the annual SAMPE meeting, Oct. 2011, Fort Worth, TX. 